\title{
Efeito de diferentes métodos de extração sobre a atividade antioxidante e o perfil de compostos fenólicos da folha de mandioca
}

\author{
Effect of different extraction methods on the antioxidant activity and phenolic \\ compounds profile of cassava leaf
}

\section{Mírian Aparecida Isidro Santosㄹ, Anderson Assaid Simão1, Tamara Rezende Marques ${ }^{1 *}$, Adelir Aparecida Sackz', Angelita Duarte Corrêa ${ }^{1}$}

${ }^{1}$ Universidade Federal de Lavras (UFLA), Departamento de Química, Lavras/MG - Brasil

\section{*Corresponding Author}

Tamara Rezende Marques, Universidade Federal de Lavras (UFLA), Departamento de Química, Campus Universitário, Caixa Postal: 3037, CEP: 37200-000, Lavras/MG - Brasil, e-mail: tamara_rezende@hotmail.com

Cite as: Effect of different extraction methods on the antioxidant activity and phenolic compounds profile of cassava leaf. Braz. J. Food Technol., v. 19, e2015067, 2016.

Received: Sept. 08, 2015; Accepted: June 08, 2016

\section{Resumo}

Folhas de mandioca (Manihot esculenta Crantz) são resíduos agroindustriais que apresentam potencial para o consumo humano, sendo fontes de proteínas, vitaminas, minerais e de substâncias antioxidantes, com destaque para os compostos fenólicos. No presente estudo, o objetivo foi identificar e quantificar os compostos fenólicos presentes em diferentes extratos da farinha de folhas de mandioca (FFM), cultivar Pão da China, e avaliar seu potencial antioxidante. A extração dos compostos fenólicos foi realizada utilizando três métodos de extração: a) refluxo com metanol/água (50:50, v/v); b) maceração com etanol/água (50:50, v/v) seguido de refluxo com acetona/água (70:30, v/v); c) maceração com metanol PA. A caracterização e quantificação foi realizada por cromatografia líquida de alta eficiência e a atividade antioxidante, determinada pelos métodos ABTS e $\beta$-caroteno/ácido linoleico. Foram encontrados cinco compostos fenólicos nos extratos da FFM: ácido gálico, galocatequina, catequina, ácido clorogênico e epigalocatequina, sendo a extração com metanol/água (50:50, v/v) a que revelou a presença do maior número destes compostos e o maior potencial antioxidante. Entre os fenólicos da FFM, independentemente do extrato, a catequina foi o majoritário. Pode-se inferir que a atividade antioxidante dos extratos da FFM está relacionada com a presença de compostos, pois a extração com maior teor desses compostos foi a que demonstrou maior potencial antioxidante.

Palavras-chave: Manihot esculenta Crantz; cv Pão da China; Resíduos agroindustriais; Atividade antioxidante; Catequina.

\section{Summary}

Cassava (Manihot esculenta Crantz) leaves are agroindustrial residues with the potential for human consumption, being sources of protein, vitamins, minerals and antioxidant substances, especially phenolic compounds. The objective of the present study was to identify and quantify the phenolic compounds present in different cassava leaf flour (FFM) extracts, from the Pão da China cultivar, and evaluate their antioxidant potential. The phenolic compounds were extracted using the following three methods: a) refluxing with methanol/water (50:50, v/v); b) maceration with ethanol/water (50:50, v/v) followed by refluxing with acetone/water $(70: 30, \mathrm{v} / \mathrm{v}) ; \mathrm{c})$ maceration with methanol PA. The compounds were identified and quantified by high performance liquid chromatography, and the antioxidant activity determined by the ABTS and $\beta$-carotene/linoleic acid methods. Five phenolic compounds were found in the FFM extracts: gallic acid, gallocatechin, catechin, chlorogenic acid and epigallocatechin, extraction with methanol/water (50:50, v/v) revealing the presence of the greatest number of these compounds and the highest antioxidant potential. Of the phenolic compounds found in FFM, catechin was the major one, independent of the extraction method. It can be inferred that the antioxidant activity of the FFM extracts is related to the presence of phenolic compounds, since the sample with the highest content of these compounds demonstrated the highest antioxidant potential.

Keywords: Manihot esculenta Crantz; cv Pão da China; Agroindustrial residues; Antioxidant activity; Catechin. 


\section{Introdução}

A mandioca (Manihot esculenta Crantz) é uma planta perene, arbustiva, pertencente à família das Euforbiáceas. Originária do continente americano, provavelmente do Brasil central, é cultivada em todo o mundo, principalmente em regiões pobres, onde constitui uma das principais explorações agrícolas, tendo elevada importância social, como principal fonte de carboidratos para mais de 700 milhões de pessoas, essencialmente em países em desenvolvimento (Empresa Brasileira de Pesquisa Agropecuária - EMBRAPA, 2014).

Nos últimos anos, tem-se dado destaque para a parte aérea da planta (folhas), que até então era tratada como subproduto agrícola, mas que, nutricionalmente, apresenta grande potencial para o consumo humano e animal. Essas folhas são ricas em proteínas, vitaminas A e C (CORRÊA et al., 2004; WOBETO et al., 2006) e minerais, especialmente Mg, Fe, Zn e Mn (WOBETO et al., 2006), obtidos a baixo custo, quando comparadas a hortaliças folhosas convencionais. Além disso, seu uso pode proporcionar renda extra a diversos produtores que vivem da cultura da mandioca.

Uma das propriedades mais almejadas em alimentos e plantas medicinais é a ação antioxidante. Antioxidantes são substâncias que combatem os radicais livres, que são espécies extremamente reativas que causam a oxidação de várias biomoléculas presentes em nosso organismo. Os antioxidantes são considerados coadjuvantes na redução do risco de desenvolvimento de doenças como aterosclerose, diabetes, hipertensão, doenças coronarianas, neurológicas degenerativas e alguns tipos de câncer (ARUOMA, 2002; VALKO et al., 2007).

Entre os antioxidantes, os compostos fenólicos têm sido alvo de muitos estudos, devido às suas ações biológicas associadas à prevenção de doenças e ao seu potencial curativo. A proteção contra doenças por esses compostos é mediada por propriedades tais como a ação de captura de radicais livres, capacidade de quelar metais de transição e reatividade como agente doador de hidrogênio e elétrons (BARREIROS et al., 2006; DIMITRIOS, 2006).

Em relação à composição fenólica das folhas de mandioca, poucos estudos são encontrados na literatura, havendo praticamente apenas relatos do seu teor (16,46 a 63,77 mg.g-1 de matéria seca) (CORRÊA et al., 2004; SIMÃO et al., 2013a) e ausência de estudos sobre a melhor forma de extração destes compostos. Assim, é importante avaliar a sua composição e diferentes formas de extração destes compostos tendo em vista que as folhas de mandioca, consideradas até então como subprodutos agrícolas, podem ser uma boa fonte dessas substâncias, o que despertaria grande interesse das indústrias farmacêutica, alimentícia e de cosméticos, acarretando valorização desse subproduto agrícola. Desta forma, o objetivo deste trabalho foi identificar e quantificar os compostos fenólicos presentes em diferentes extratos da farinha de folhas de mandioca e avaliar seu potencial antioxidante.

\section{Material e métodos}

Folhas maduras de mandioca (Manihot esculenta Crantz cv. Pão da China) livres de pragas e doenças foram coletadas no período da manhã, no mês de abril de 2012, aos 12 meses de idade no Departamento de Agricultura da Universidade Federal de Lavras, Lavras, Minas Gerais (2114'06" de latitude Sul e 4500'00" de latitude Oeste, a uma altitude média de $918 \mathrm{~m}$ ). As folhas, lavadas em água corrente e água destilada, foram, em seguida, submetidas à secagem em estufa com circulação de ar, por período de 48 horas, à temperatura de $35 \pm 2{ }^{\circ} \mathrm{C}$. Depois da secagem, as folhas tiveram seus pecíolos retirados e foram moídas em moinho do tipo Willey para a obtenção da farinha de folhas de mandioca (FFM).

Os compostos fenólicos presentes na FFM foram extraídos de três formas. A primeira extração foi realizada de acordo com a metodologia descrita por Simão et al. (2013b), em que $1 \mathrm{~g}$ de FFM em 50 mL de metanol/água (50:50, v/v) foi mantido em refluxo por 15 minutos a $80^{\circ} \mathrm{C}$, por três vezes consecutivas, e os extratos foram reunidos e evaporados, a $80^{\circ} \mathrm{C}$, até $25 \mathrm{~mL}$.

Na segunda extração, seguiu-se a metodologia de extração de antioxidantes descrita por Rufino et al. (2006). A FFM foi mantida sob maceração em etanol/água (50:50, v/v) na proporção 1:40 (m/v) por 30 minutos e, em seguida, centrifugada a $2.500 \times$ g durante 15 minutos. O sobrenadante foi recolhido e o precipitado foi novamente submetido ao processo de extração descrito acima, porém desta vez com acetona/água $(70: 30, v / v)$. Os dois sobrenadantes foram reunidos e concentrados em evaporador rotatório a $60^{\circ} \mathrm{C}$ até $25 \mathrm{~mL}$.

Na terceira extração, a FFM foi mantida sob maceração em metanol PA durante 48 horas na proporção de 1:1,5 (m/v) e, em seguida, filtrada com algodão hidrófilo. Ao resíduo foi adicionado mais metanol, sendo esse procedimento repetido sete vezes para garantir um bom rendimento da extração.

Os reagentes, metanol e etanol, usados na extração dos compostos fenólicos presentes na FFM, foram da Merck $^{\circledR}$ (Darmstadt, Germany).

As análises cromatográficas de compostos fenólicos foram realizadas utilizando-se um cromatógrafo a líquido (Agilent, modelo 1100, USA), equipado com uma bomba binária, injetor automático e detector com arranjo de diodos, no comprimento de onda $280 \mathrm{~nm}$. Os extratos fenólicos e os padrões foram separados em uma coluna ascentis $C_{18}(250 \mathrm{~mm} \times 4,6 \mathrm{~mm}, 5 \mu \mathrm{m})$, conectada a uma 
pré-coluna ascentis $\mathrm{C}_{18}(20 \mathrm{~mm} \times 4,0 \mathrm{~mm}, 5 \mu \mathrm{m})$. A fase móvel foi composta pelas soluções: ácido acético $2 \%$ (A), e metanol:água:ácido acético 70:28:2 (v/v/v) (B). Foi utilizado o seguinte sistema gradiente: $100 \%$ do solvente A até 5 minutos, $70 \%$ de $A$ até 25 minutos, $60 \%$ de $A$ em 43 minutos, $55 \%$ de $A$ em 50 minutos. Empregaram-se vazão de $1 \mathrm{~mL} \cdot \mathrm{min}^{-1}$, temperatura de $15^{\circ} \mathrm{C}$ e o volume de injeção foi de $20 \mu \mathrm{L}$.

Os padrões fenólicos utilizados foram preparados em metanol (Merck ${ }^{\circledR}$, Darmstadt, Germany) em um intervalo de concentração que variou de: ácido gálico $\left(0,34-42,53 \mathrm{mg} \cdot \mathrm{L}^{-1}\right)$, galocatequina $\left(7,32-90,53 \mathrm{mg} . \mathrm{L}^{-1}\right), 3,4$-di-hidroxibenzeno (12,33-52,53 mg. L-1 $)$, catequina $\left(2,90-127,72 \mathrm{mg} \cdot \mathrm{L}^{-1}\right)$, ácido clorogênico $\left(35,43-177,15 \mathrm{mg} \cdot \mathrm{L}^{-1}\right)$, epigalocatequina (0,45-26,21 mg.L-1 $)$ ácido vanílico (8,34-62,53 mg. L-1 $)$, cafeico (15,31-63,06 mg. $\left.\mathrm{L}^{-1}\right)$, ácido siríngico $\left(0,59-7,93 \mathrm{mg} \cdot \mathrm{L}^{-1}\right)$, ácido p-cumárico $\left(0,88-52,53 \mathrm{mg} \cdot \mathrm{L}^{-1}\right)$, ácido ferúlico (0,54-32,53 mg. L-1 ) e ácido m-cumárico (0,23-0,72 mg.L-1 $)$, todos da marca Sigma-Aldrich (St. Louis, MO, EUA). Os padrões fenólicos foram adquiridos da Sigma-Aldrich ${ }^{\circledR}$ (St. Louis, MO, USA). Os reagentes, ácido acético e metanol, usados na preparação da fase móvel, foram da Merck ${ }^{\circledR}$ (Darmstadt, Germany) e a água ultrapura foi obtida pelo sistema Milli-Q (Millipore, Billerica, MA, EUA).

Os extratos fenólicos e os padrões foram filtrados em membrana de nylon de 0,45 $\mu \mathrm{m}$ da Millipore ${ }^{\circledR}$ (Bedford, MA, USA) e diretamente injetados no sistema cromatográfico $(n=3)$. Os compostos fenólicos nos extratos foram identificados por comparação com os tempos de retenção dos padrões e por adição de padrão conhecido à solução para verificação da coeluição dos padrões com as amostras. A quantificação foi realizada por meio da construção de curvas analíticas para cada padrão $(n=6)$.

A atividade antioxidante foi medida por duas metodologias. A primeira consistiu na determinação da inibição da peroxidação lipídica pelo método $\beta$-caroteno/ácido linoleico, em que se utilizou a metodologia desenvolvida por Rufino et al. (2006).

Em tubos de ensaio, 0,2 mL de cada extrato da FFM (1.000 mg.L-1 ) foi adicionado a 2,5 mL da solução sistema $\beta$-caroteno/ácido linoleico. Foram feitos tubos controle contendo $2,5 \mathrm{~mL}$ da solução sistema $\beta$-caroteno/ácido linoleico com 0,2 mL de BHT (butil-hidroxitolueno antioxidante sintético), quercetina e rutina, que são flavonoides com a atividade antioxidante comprovada, todos na concentração de $200 \mathrm{mg} \cdot \mathrm{L}^{-1}$. Os tubos padrões e testes foram colocados em banho-maria a $40^{\circ} \mathrm{C}$ e, após 2 horas, os tubos foram homogeneizados e as leituras foram feitas em $470 \mathrm{~nm}$, utilizando-se água para calibrar o espectrofotômetro modelo UV-VIS, Quimis.

A segunda metodologia empregada (método ABTS) foi a descrita por Re et al. (1999). Nos extratos foram feitas quatro diluições (500, 1.000, 2.000 e 4.000 mg.L-1 $)$ para os ensaios e posterior construção de curva analítica.
$O$ radical $A B T S \cdot$ forma-se pela adição de $5 \mathrm{~mL}$ de solução estoque de ABTS 7 mmol.L-1 com $88 \mu \mathrm{L}$ de solução de persulfato de potássio $140 \mathrm{mmol} . \mathrm{L}^{-1}$ e mantidos no escuro por 16 horas. O radical formado é diluído em etanol até obter uma absorbância de 0,70 \pm 0,05, devendo ser utilizada apenas no dia da análise. Em ambiente escuro, 3,0 $\mathrm{mL}$ do radical ABTS ${ }^{\bullet}$ foram colocados em um tubo de ensaio com uma alíquota de $30 \mu \mathrm{L}$ de cada diluição dos extratos, homogeneizados em agitador, e a leitura (734 nm) foi feita após 6 minutos de reação, utilizando-se etanol na calibração do espectrofotômetro.

Foram realizadas curvas analíticas com trolox (6-hidroxi-2,5,7,8-tetrametilcroman-2-ácido carboxílico) (100 a $200 \mu \mathrm{mol} . \mathrm{L}^{-1}$ ), além de teste para comparação com os padrões BHT, rutina e quercetina, preparados na concentração de $200 \mathrm{mg} \cdot \mathrm{L}^{-1}$.

Todas as análises foram realizadas em três repetições e os resultados apresentados como a média \pm desvio padrão. Os dados foram avaliados estatisticamente por análise de variância e as médias comparadas pelo teste Scott Knott $(P<0,05)$ com o auxílio do software $R$ (R DEVELOPMENT CORE TEAM, 2012).

\section{Resultados e discussão}

Na Figura 1, são mostrados os cromatogramas dos compostos fenólicos dos três extratos da FFM e dos padrões de compostos fenólicos. Na Tabela 1, constam os teores dos compostos fenólicos dos três extratos da FFM. Verificou-se que os diferentes sistemas de extração utilizados afetaram os tipos e os teores de fenólicos da FFM. A extração com metanol/água (50:50, v/v) revelou a presença do maior número de compostos fenólicos na FFM, apresentando também os maiores teores de catequina e ácido gálico. Observou-se também que, entre os fenólicos da FFM, independentemente da técnica de extração, a catequina foi majoritária.

Além do processo de extração dos compostos fenólicos, outros fatores afetam o conteúdo destes compostos em folhas de mandioca. Wobeto et al. (2007), estudando folhas de mandioca na idade de 12, 15 e 17 meses, verificaram que os níveis de compostos fenólicos destas folhas aumentaram com a maturidade da planta. A temperatura de secagem das folhas para a produção da farinha de folha de mandioca é outro fator que afeta os níveis de compostos fenólicos, tendo sido observado que temperaturas superiores acarretaram menores teores (CORRÊA et al., 2004).

A atividade antioxidante determinada pelo método ABTS e pelo método $\beta$-caroteno/ácido linoleico dos extratos da FFM é mostrada na Tabela 2. Dos extratos analisados, o metanol/água (50:50, v/v) foi o que mostrou maior potencial antioxidante, tanto para o método ABTS, quanto para o método $\beta$-caroteno/ácido linoleico. Tal fato é explicado, 
Efeito de diferentes métodos de extração sobre a atividade antioxidante e o perfil de compostos fenólicos da folha de mandioca Isidro Santos, M. A. et al.

provavelmente, pelo maior número e concentração de compostos fenólicos neste extrato. Além da concentração, o efeito sinérgico entre os compostos fenólicos também deve ser levado em consideração.

Em análise do potencial antioxidante de cinco plantas medicinais (Aloe vera, Simaba ferruginea, Baccharis trimera,
Garcinia cambogia e Tournefortia paniculata), Simão et al. (2013b) observaram que as plantas com maiores teores de compostos fenólicos apresentaram o maior potencial antioxidante, tanto pelo método ABTS quanto pelo método $\beta$-caroteno/ácido linoleico, corroborando com os resultados deste trabalho.

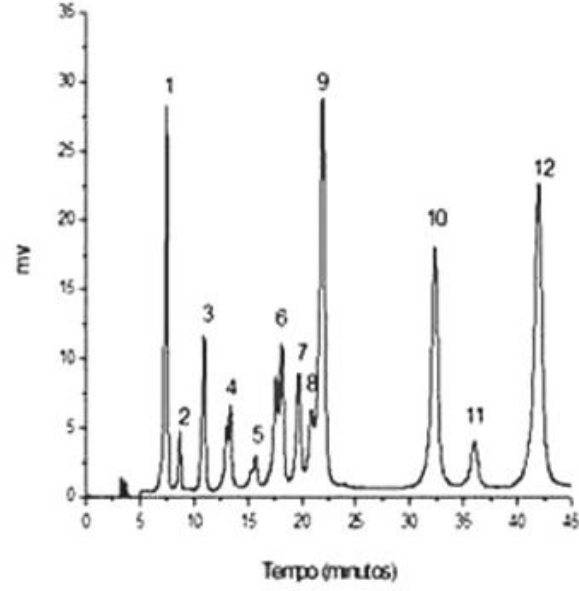

(A)

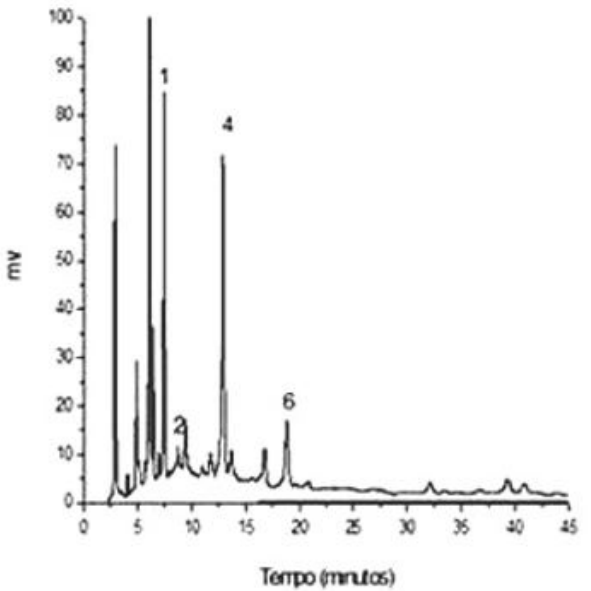

(C)

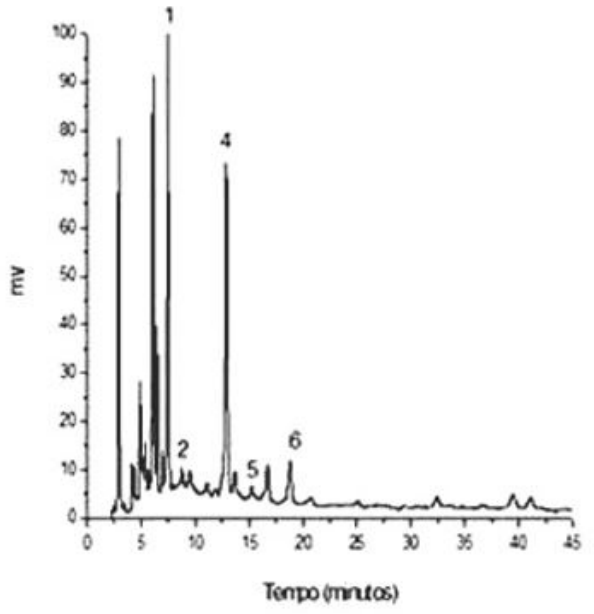

(B)

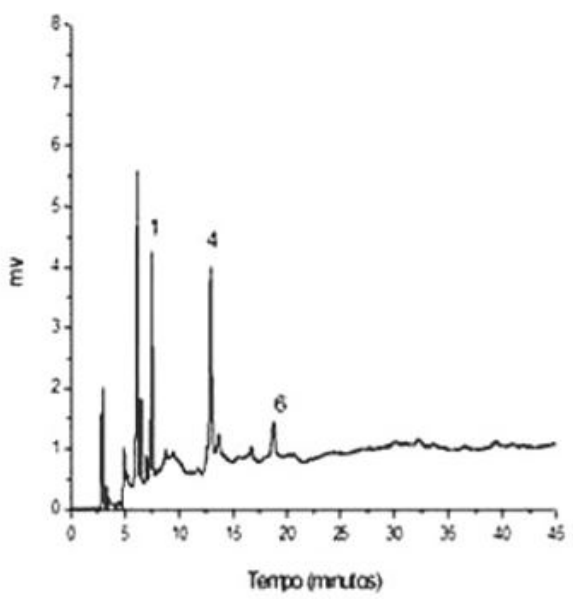

(D)

Figura 1. Cromatogramas dos compostos fenólicos em farinha de folhas de mandioca. (A) Identificação dos padrões: $1=$ ácido gálico, 2 = galocatequina, 3 =3,4 di-hidroxibenzeno, 4 = catequina, 5 = ácido clorogênico, $6=$ epigalocatequina, 7 = ácido vanílico, 8 = epicatequina, 9 = ácido siríngico, 10 = ácido p-cumárico, 11 = ácido ferúlico, 12 = ácido m-cumárico. (B) Extração com metanol/água (50:50, v/v). (C) Extração com etanol/água (50:50, v/v)/acetona/água (70:30, v/v). (D) Extração com metanol PA.

Tabela 1. Compostos fenólicos, em mg.100 g-1 em três extratos da farinha de folhas de mandioca.

\section{Compostos fenólicos}

Extrato $1^{*}$

Extrato $2^{* *}$

\section{Extrato $3^{* * *}$}

Catequina

$208,00 \pm 2,10^{2 \mathrm{~A}}$

$155,96 \pm 14,07^{\mathrm{ac}}$

$191,00 \pm 1,13^{\mathrm{aB}}$

Ácido gálico

$43,00 \pm 1,98^{\mathrm{bA}}$

$33,00 \pm 0,42^{\mathrm{bB}}$

$35,00 \pm 1,37^{\mathrm{bB}}$

Epigalocatequina

$22,52 \pm 3,61^{\mathrm{cA}}$

$19,30 \pm 1,85^{\mathrm{cA}}$

$16,1 \pm 0,99$ св

Ácido clorogênico

$9,65 \pm 1,38^{\mathrm{d}}$

$9,10 \pm 0,57^{\mathrm{eA}}$

$9,10 \pm 2,37^{\mathrm{dA}}$

Dados são a média de 3 repetições + desvio padrão *extrato 1: Metanol/água (50:50 v/v): **extrato 2: Etanol/água (50:50, v/v)/ acetona/água (70:30, v/v); ${ }^{\star *}$ extrato 3: Metanol PA. Letras minúsculas nas colunas compararam os compostos fenólicos e maiúsculas nas linhas compararam os extratos. Mesmas letras não diferem entre si pelo teste de Scott-Knott, a 5\% de probabilidade. 
Tabela 2. Atividade antioxidante dos extratos da farinha de folhas de mandioca pelos métodos ABTS e $\beta$-caroteno/ácido linoleico.

\begin{tabular}{|c|c|c|}
\hline Extratos & $\begin{array}{c}\text { ABTS } \\
\left(\mu \mathrm{mol} \text { trolox } \mathrm{L}^{-1} \mathrm{~g}^{-1}\right)\end{array}$ & $\begin{array}{c}\beta \text {-caroteno/ ácido linoleico } \\
\text { (\% de inibição) }\end{array}$ \\
\hline Extrato $1^{*}\left(1.000 \mathrm{mg} \cdot \mathrm{L}^{-1}\right)$ & $383,33 \pm 0,67^{d}$ & $87,53 \pm 0,57^{b}$ \\
\hline Extrato $2^{* *}\left(1.000 \mathrm{mg} \cdot \mathrm{L}^{-1}\right)$ & $330,93 \pm 1,27^{e}$ & $83,52 \pm 0,53^{c}$ \\
\hline Extrato $3^{\star \star \star}\left(1.000 \mathrm{mg} \cdot \mathrm{L}^{-1}\right)$ & $233,17 \pm 0,75^{\dagger}$ & $79,71 \pm 0,83^{d}$ \\
\hline \multicolumn{3}{|l|}{ Padrões } \\
\hline Quercetina (200 mg. $\mathrm{L}^{-1}$ ) & $3.984,06 \pm 117,10^{a}$ & $77,33 \pm 0,91^{e}$ \\
\hline Rutina (200 mg. $\left.\mathrm{L}^{-1}\right)$ & $1.043,30 \pm 11,27^{c}$ & $17,42 \pm 0,75^{\dagger}$ \\
\hline BHT (200 mg. L-1) & $1.897,53 \pm 95,93^{b}$ & $100,40 \pm 0,34^{a}$ \\
\hline
\end{tabular}

Dados são a média de 3 repetições \pm desvio padrão. *extrato 1: Metanol/água (50:50 v/v); **extrato 2: Etanol/água (50:50 v/v) seguido de acetona/água (70:30 v/v); ;** extrato 3: Metanol PA. Mesmas letras nas colunas não diferem entre si pelo teste de Scott-Knott, a 5\% de probabilidade.

O bom potencial antioxidante dos extratos da FFM no método ABTS $\left(233,17\right.$ a $383,33 \mu \mathrm{mol}$ trolox $\left.\mathrm{L}^{-1} \cdot \mathrm{g}^{-1}\right)$ é evidenciado quando comparado a outros estudos, nos quais, independentemente dos extratos, superou o encontrado por Soares et al. (2008), em duas cascas de uvas, em umol trolox L-1. $\mathrm{g}^{-1}$ matéria seca: 'Isabel' $(89,22)$ e 'Niágara' $(157,31)$; e os de resíduos agroindustriais de vinho: $(98,9)$ (CATANEO et al., 2008); e os detectados por Wojdylo et al. (2007), em 32 ervas polonesas, que verificaram potenciais entre 0,0045 (Archangelica officinalis) e 3,46 (Syzygium aromaticum) $\mu \mathrm{mol}$ trolox $\mathrm{L}^{-1} \cdot \mathrm{g}^{-1}$ matéria seca.

Observou-se que o potencial antioxidante dos extratos da FFM no método ABTS em comparação aos padrões obteve em média menos que $50 \%$ do potencial desses padrões. Entretanto, como as substâncias presentes nos extratos da FFM não se encontram de forma isolada como os padrões, pode-se considerar o potencial apresentado pelos extratos como um bom potencial antioxidante.

No método -caroteno/ácido linoleico, os extratos da FFM demonstraram maior potencial que a quercetina e rutina, sendo menor apenas que o BHT. Essas diferenças de respostas antioxidantes entre os dois métodos, em relação aos extratos da FFM e aos padrões analisados, podem ser inerentes às características, mecanismo de ação dos compostos bioativos e também ao princípio do método utilizado para avaliar sua propriedade antioxidante (DUARTE-ALMEIDA et al., 2006; HUANG et al., 2005).

Ramalho e Jorge (2006) realizaram uma revisão, reportando estudos sobre potencial antioxidante de substâncias naturais e sintéticas na conservação de óleos, gorduras e alimentos gordurosos e verificaram que os ácidos clorogênico, gálico, protocatequínico e cafeico, quando empregados na conservação do óleo de girassol, apresentaram melhor efetividade que BHA e BHT, evidenciando a ótima ação antioxidante desses compostos fenólicos presentes em alimentos e plantas medicinais. Como na FFM foram identificados alguns desses compostos fenólicos (ácidos gálico e clorogênico), esta farinha se credencia para ser utilizada como fonte de antioxidantes naturais.
Estudos realizados por Melo et al. (2007) com FFM obtida da cultivar Cacao mostraram que dietas contendo 10\% e 15\% desta farinha propiciaram redução nos níveis plasmáticos de substâncias reativas ao ácido tiobarbitúrico em ratos Wistar, confirmando o potencial antioxidante in vivo da FFM. Porém estes autores não concluíram quais substâncias foram responsáveis pela redução de substâncias reativas ao ácido tiobarbitúrico, mas, provavelmente, os compostos fenólicos presentes na farinha desta cultivar contribuíram para esta ação.

Além dos compostos fenólicos, a vitamina C e os carotenoides relatados por Simão et al. (2013a), em estudo sobre o potencial antioxidante de várias cultivares de folhas de mandioca, também podem ter contribuído para a atividade antioxidante observada neste trabalho.

\section{Conclusão}

A extração usando o solvente metanol/água (50:50, $\mathrm{v} / \mathrm{v}$ ) foi a mais eficaz para a obtenção dos compostos fenólicos da farinha de folhas de mandioca, apresentando também a maior atividade antioxidante. Foram identificados os seguintes compostos fenólicos na FFM: catequina, ácido gálico, epigalocatequina, ácido clorogênico e galocatequina. Entre esses, a catequina foi a majoritária.

Pode-se inferir que a farinha de folhas de mandioca é fonte de compostos fenólicos e, possivelmente, pode ser utilizada como fonte natural de antioxidantes em preparações farmacológicas e alimentícias.

\section{Agradecimentos}

Agradecemos à Fundação de Amparo à Pesquisa do Estado de Minas Gerais (FAPEMIG), à Coordenação de Aperfeiçoamento de Pessoal de Nível Superior (CAPES) e ao Conselho Nacional de Desenvolvimento Científico e Tecnológico (CNPq) as bolsas concedidas.

\section{Referências}

ARUOMA, O. I. Neuroprotection by dietary antioxidants: new age of research. Die Nahrung, Nahrung, v. 46, n. 6, p. 381-382, 2002. http://dx.doi.org/10.1002/1521-3803(20021101)46:6<381::AIDFOOD381>3.0.CO;2-T. PMid:12577583. 
Efeito de diferentes métodos de extração sobre a atividade antioxidante e o perfil de compostos fenólicos da folha de mandioca Isidro Santos, M. A. et al.

BARREIROS, A. L. B. S.; DAVID, J. M.; DAVID, J. P. Estresse oxidativo: relação entre geração de espécies reativas e defesa do organismo. Química Nova, São Paulo, v. 29, n. 1, p. 113-123, 2006.

CATANEO, C. B.; CALIARI, V.; GONZAGA, L.; KUSKOSKI, L. M.; FETT, R. Atividade antioxidante e conteúdo fenólico do resíduo agroindustrial da produção de vinho. Ciências Agrárias, Londrina, v. 29, n. 1, p. 93-102, 2008.

CORRÊA, A. D.; SANTOS, S. R.; ABREU, C. M. P.; JOKL, L.; SANTOS, C. D. Removal of polyphenols of the flour cassava leaves. Ciência e Tecnologia de Alimentos, Campinas, v. 24, n. 2, p. 159-164, 2004

DIMITRIOS, B. Source of natural phenolics antioxidants. Trends in Food Science \& Technology, Reino Unido, v. 17, n. 9, p. 505-512, 2006.

DUARTE-ALMEIDA, J. M.; SANTOS, R. J.; GENOVESE, M. I.; LAJOLO, F. M. Avaliação da atividade antioxidante utilizando sistema b-caroteno/ácido linoléico e método de seqüestro de radicais DPPH. Ciência e Tecnologia de Alimentos, Campinas, v. 26, n. 2, p. 446-452, 2006.

EMPRESA BRASILEIRA DE PESQUISA AGROPECUÁRIA EMBRAPA. Mandioca e fruticultura. Brasília, 2014. Disponível em: <http://www.cnpmf.embrapa.br/index.php?p=pesquisaculturas_pesquisadas-mandioca.php>. Acesso em: 11 out. 2014.

HUANG, D.; OU, B.; PRIOR, R. L. The chemistry behind antioxidant capacity assays. Journal of Agricultural and Food Chemistry, London, v. 53, n. 6, p. 1981-1856, 2005. PMid:15769103.

MELO, D. S.; CORRÊA, A. D.; MARCOS, F. C. A.; SOUSA, R. V.; ABREU, C. M. P.; SANTOS, C. D. Effects of cassava leaf flour on lipidic peroxidation blood lipidic profile and liver weight of rats. Ciência e Agrotecnologia, Lavras, v. 31, n. 2, p. 420-428, 2007.

RAMALHO, V. C.; JORGE, N. Antioxidantes utilizados em óleos gorduras e alimentos gorduras. Química Nova, São Paulo, v. 29, n. 4, p. 755-760, 2006

RE, R.; PEllegrinI, N.; PROTEGgente, A.; PANNAlA, A.; YANG, M.; RICE-EVANS, C. Antioxidant activity applying an improved ABTS radical cation decolorization assay. Free Radical Biology and Medicine, Oxford, v. 26, n. 9, p. 1231-1237, 1999.
R DEVELOPMENT CORE TEAM. R: a language and environment for statistical computing. Viena: R Foundation for Statistical Computing, 2012.

RUFINO, M. S. M.; ALVES, R. S.; BRITO, E. S.; MANCINI FILHO, J.; MOREIRA, A. V. B. Determination of total antioxidant activity in fruit by the method $\beta$-caroteno/ácido linoleic. Fortaleza: Embrapa Agroindústria Tropical, 2006. 4 p.

SIMÃO A. A.; ISIDRO M. A.; FRAGUAS R. M.; MARQUES T. R.; DUARTE M. H.; SANTOS C. M.; FREIRE J. M.; CORRÊA A. D. Antioxidants and chlorophyll in cassava leaves at three plant ages. African Journal of Agricultural Research, Nairóbi, v. 8 , n. 25, p. 2.650-2.658, 2013a.

SIMÃO, A. A.; LAGE, F. F.; CHAGA, P. M. B.; FRAGUAS, R. M.; FREIRE, J. M.; MARQUES, T. R.; CORREAA, A. D. Antioxidants from medicinal plants used in the treatment of obesity. European Journal of Medicinal Plants, India, v. 3, n. 3, p. 429-443, 2013 b. http://dx.doi.org/10.9734/EJMP/2013/3095.

SOARES, M.; WELTER, L.; KUSKOSKI, E. M.; GONZAGA, L.; FETT, R. Compostos fenólicos e atividade antioxidante da casca de uvas Níagara e Isabel. Revista Brasileira de Fruticultura, Cruz das Almas, v. 30, n. 1, p. 59-64, 2008.

VALKO, M.; LEIBFRITZ, D.; MONCOL, J.; CRONIN, M. T.; MAZUR, M.; TELSER, J. Free radicals and antioxidants in normal physiological functions and human disease. The International Journal of Biochemistry \& Cell Biology, Australia, v. 39, n. 1, p. 44-84, 2007. http://dx.doi.org/10.1016/j.biocel.2006.07.001. PMid:16978905

WOBETO, C.; CORRÊA, A. D.; ABREU, C. M. P.; SANTOS, C. D.; ABREU, J. R. Nutrients in the cassava (Manihot esculenta Crantz) leaf powder at three ages of the plant. Ciência e Tecnologia de Alimentos, Campinas, v. 26, n. 4, p. 865-869, 2006.

WOBETO, C.; CORRÊA, A. D.; ABREU, C. M. P.; SANTOS, C. D.; PEREIRA, H. V. Antinutrients in the cassava (Manihot esculenta Crantz) leaf powder at three ages of the plant. Ciência e Tecnologia de Alimentos, Campinas, v. 27, n. 1, p. 108-112, 2007.

WOJDYLO, A.; OSMIANSKI, J.; CZERMERYS, R. Antioxidant activity and phenolic compounds in 32 selected herbs. Food Chemistry, London, v. 105, n. 3, p. 940-949, 2007. 